dicarboxylic aciduria, and the presence of hexanoylglycine and suberylglycine was confirmed by gas chromatography-mass spectrometry. $\mathrm{He}$ had appreciable reduction in free and total plasma carnitine concentrations (both less than $10 \mu \mathrm{mol} / \mathrm{l}$ ) and excreted phenyl propionyl glycine after a phenyl propionate load. MCAD deficiency was confirmed by a reduced activity of $1{ }^{14} \mathrm{C}$-octanoate oxidation $(0.68 \mathrm{nmol}$ carbon dioxide $\left(\mathrm{CO}_{2}\right)$ /hour/mg protein; controls $2 \cdot 1$ $3.6 \mathrm{nmol} \mathrm{CO} /$ hour $/ \mathrm{mg}$ protein) in cultured skin fibroblasts (G Besley, Royal Hospital for Sick Children, Edinburgh). He was discharged on treatment with phenobarbitone but despite therapeutic concentrations he continued to have fits of short duration. The family was given instructions about a high carbohydrate, low fat diet and a detailed plan about his management during any intercurrent illness.

At the age of 18 months he was found one morning convulsing in bed, no abnormality was found on admission, and he was allowed home. Two days later he became mildly unwell, vomited once, and was given several high carbohydrate drinks. He recovered during the day only to be found dead the next morning. On postmortem examination no abnormality was found. In particular frozen sections of the liver were stained for oil red 0 and showed only slight fatty change and not the panlobular steatosis that has been described.

\section{Discussion}

The poor outcome in this case emphasises the mortality associated with MCAD deficiency. However, most of the patients with MCAD deficiency who have died suddenly have a history of poor feeding during an intercurrent illness. This patient is unusual in that he received a high carbohydrate intake during his illness which, although it appeared to limit fat accumulation in the liver, did not prevent his death. It may therefore be necessary to give carnitine supplements and to continue a high carbohydrate intake during recovery from an acute illness.

An alternative explanation is that death may have been due to an epileptic fit but, although recognised as a cause of sudden, unexpected death, it is very rare in children. ${ }^{4}$ It seems more likely that this patient died as a result of a fatty acid oxidation defect.

The absence of significant fatty infiltration of the liver has important implications for investigation of SIDS as it suggests that fatty change cannot be used as a reliable screening test to identify a high risk group likely to have a defect of fatty acid oxidation.

1 Nyhan WL. Abnormalities of fatty acid oxidation. N Engl Med 1988;319:1344-6.

2 Bennett MJ, Allison F, Pollitt RJ, Variend S. Fatty acid oxidation defects as causes of unexpected death in infancy. In: Tanaka K, Coates PM, eds. Fatty acid oxidation. New In: Tanaka K, Coates

3 Editorial. Sudden infant death and inherited disorders of fat oxidation. Lancet 1986;ii:1073-5.

4 Dashieff RM, Dickinson LJ. Sudden unexpected death of epileptic patient due to cardiac arrhythmia after seizure. Arch Neurol 1986;43:194-6.
Statham Grove Surgery, Statham Grove, Stoke Newington, London N16 9DP

Correspondence to Dr Goodhart.

Accepted 21 January 1991

(ArchDisChild 1991;66:728-730).

\title{
General practitioner training needs for child health surveillance
}

\author{
L C Goodhart
}

\begin{abstract}
A postal questionnaire was sent to 136 Hackney general practitioners inquiring about their plans for child health surveillance. A total of 112 responded and detailed their training needs, both practical and theoretical. Ninety one responders were providing or planning to provide surveillance. Responders were eager for further training particularly in premature baby follow up, mental handicap, speech and hearing assessment, and social and behavioural problems.
\end{abstract}

For some years there have been proposals to develop the role of general practitioners in child health surveillance. In 1976 the Court report proposed that there should be general practitioner paediatricians, ${ }^{1}$ but the General Medical Services Committee and the Royal College of General Practitioners felt unable to support this ${ }^{2}$ because it undermined the strength of the general practitioner as a generalist.

As the health and development of young children are so closely related to family circumstances, it is right that child health surveillance should be regarded as part of family medicine. General practitioners can bring together preventive and therapeutic care to provide a fully integrated child health service, a concept that is now firmly supported by general practitioners and paediatricians alike. However, the inclusion of paediatric surveillance in the new contract requires evidence of additional training if general practitioners are to be remunerated for this work.

In a 1985 survey of the qualifications of, and services provided by, general practitioners in the north of England, Marsh concluded that developmental screening, and even general paediatrics, was not yet safe with general practitioners. $^{3}$ Similarly Wilmot, who ques- 
tioned general practitioner trainees, showed that although $72 \%$ had worked in hospital paediatrics and $66 \%$ wanted to provide child health surveillance, only $34 \%$ felt confident to do so. ${ }^{4}$

After work to define the knowledge, skills, and attitudes general practitioners need to provide child health surveillance, recommendations have been made on the training objectives. ${ }^{5}$ However, there has been little consultation with family doctors to determine their perceived educational needs.

This study was organised to ensure that proposed training courses would be tailored to local need, but the results may also reflect the needs of general practitioners nationally.

\section{Methods}

A questionnaire was sent to all Hackney general practitioners inquiring about the plans for child health surveillance services, and to discover their perceived training needs.

In Hackney, developmental checks are normally done at 6 weeks and 15 months of age by a doctor (general practitioner or community medical officer), and at 8 months and 2.5 years by a health visitor. The general practitioners were asked whether their practice provided all these preschool checks and were considered to do so whether health visitor checks were done at the surgery or a local health centre.

The doctors were asked about their qualifications, training, and experience and whether they 'felt confident' or would 'welcome further training' in 19 relevant topics.

Reminders were sent after one month and non-responders were contacted by telephone to determine whether they intended to provide child health surveillance.

\section{Results}

A total of 112 of the 136 general practitioners ( $82 \%$ response) including five of the seven trainees returned the questionnaire. Ninety one of the responders (including three trainees) were from practices who were providing or planning to provide child health surveillance. All other practices were successfully contacted by telephone to determine their intentions to provide child health surveillance. The 24 nonresponders were spread between practices who were already providing $(n=8)$ or planning child health surveillance $(n=7)$, those who were not $(n=7)$, and trainees $(n=2)$. However, only six of the non-responders had personally applied to join the child health surveillance list.

Table I General practitioners' plans to provide child health surveillance $(n=129)^{*}$ No(\%) principals

Definitely continue 49 (38) 3 (2)
Probably continue Definitely start $27(21)$ Probably start 8 (6) Will not start 41 (32) Plan to stop $\quad 1$ (1)

${ }^{*}$ Excludes seven trainees.

\section{GENERAL PRACTITIONERS' INTENTIONS}

All the general practitioner principals were asked whether they already provided 'all preschool checks', and whether they were likely to start or continue to provide this service in the next year (see table 1).

\section{EXPERIENCE}

Altogether $35(38 \%)$ of the 91 responders from practices likely to provide all preschool checks had held a paediatric post with 'some training in developmental paediatrics'. For most this was during a hospital job, although some had also worked in the community. Nearly half of the doctors felt they had gained their experience in a general practitioner run child health surveillance clinic. Thirty one (34\%) general practitioners had attended a postgraduate course in developmental paediatrics and $19(21 \%)$ had the Diploma in Child Health or MRCP specialising in paediatrics (see table 2).

\section{PERCEIVED TRAINING NEEDS}

The doctors were asked whether they wanted further training in all the topics and whether this should be theoretical, practical, or both. The perceived training needs are shown in the figure as responders who wanted further training in each subject. It was interesting that the perceived training needs of doctors who had first hand experience of child health surveillance were very similar to those who had not.

Follow up of premature babies and mental handicap featured high in the list of training needs, as did the social development and behavioural problems of children. General practitioners wanted to learn more about child abuse but felt that they needed practical experience. They particularily requested practical training for speech and hearing assessment, and for the milestone checks of older preschool children. Paediatric orthopaedics and dental health promotion also stood out as gaps in knowledge.

Table 2 Experience in developmental paediatrics

\begin{tabular}{ll}
\hline & $\begin{array}{l}\text { No(\%) } \\
\text { of doctors* }\end{array}$ \\
\hline $\begin{array}{l}\text { Hospital paediatric job } \\
\text { Community paediatric job }\end{array}$ & $30(33)$ \\
$\begin{array}{l}\text { General practitioner run child health surveillance } \\
\text { clinic }\end{array}$ & $42(17)$ \\
$\begin{array}{l}\text { Postgraduate course } \\
\text { Diploma of Child Health or MRCP in paediatrics }\end{array}$ & $31(34)$ \\
\hline
\end{tabular}

${ }^{*}$ Some doctors had more than one type of experience.

Theoretical only Both Practical only

Premature baby follow up Speech assessment Child abuse

Behaviour problems Mental handicap Family therapy Hearing assessment Orthopedic problems 2-3 year check Sleep disturbance 15-18 month check Dental health Enuresis

Baby clinic administration

Heart murmurs

BCG technique

Medical or surgical problems 6 week check

Immunisation policy

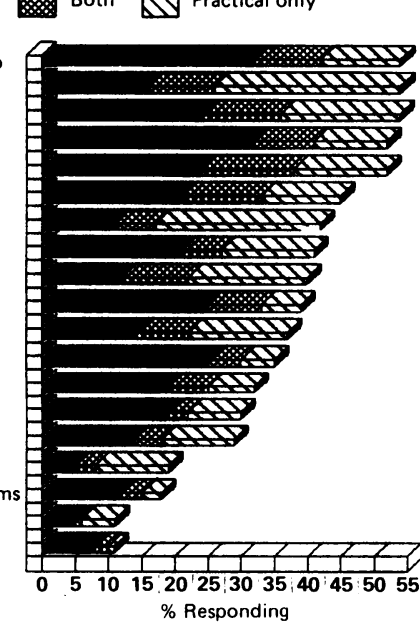

Training needs of 91 Hackney general practitioners who provided or were planning to provide child health surveillance (includes three trainees). 
There was, however, relative confidence with regard to immunisations, 6 week checks, heart murmurs, and other medical and surgical problems, which were perhaps well covered by vocational training.

\section{Discussion}

This study was done in a deprived inner city area where previous training and experience in paediatric surveillance has been low compared with other parts of the country. ${ }^{6}$ The high response rate suggests enthusiasm towards child health surveillance and an eagerness for appropriate training. General practitioners were fairly clear about the areas in which they wanted more training and opinion tended to be consistent.

As general practitioners perform more paediatric surveillance the health authority role may change, with training and advice for general practitioners becoming as important as providing clinical services. While theoretical courses can readily be tailored to address gaps in knowledge, the high demand for practical training has implications for community services. Speech therapy and audiology departments, district handicap teams, child guidance and social services could all provide training on an individual or small group basis.

The fact that so many doctors gain their experience of child health surveillance within general practice suggests that the training role of these general practice clinics should be recognised and enhanced. This could be achieved through regular support from senior community paediatricians, perhaps visiting and contributing to after clinic meetings.

The key to a successful child health programme lies in the relationship between doctors, health visitors, and others in the community health services. Multidisciplinary refresher training is one way to strengthen these links at the grass roots but such courses must address specific needs. Although this survey provides information about the topics general practitioners would wish to cover, it would be helpful to have the same information from the other professionals.

1 Committee on Child Health Services. Fit for the future. London: HMSO, 1976:448. (Court report.) (Cmmd 6680.) 2 Donald AG, chairman. The care of children-college policy. I R Coll Gen Pract 1978;28:553-6.

3 Marsh GN, Russell D, Russell I. Is paediatrics safe in general practitioners' hands? A study in the north of England. $\mathcal{F} R$ Coll Gen Pract 1989;39:138-41.

4 Wilmot JF. Preparation for paediatric surveillance. A survey of trainee general practitioners. The Practitioner 1984;228: 975-7.

5 Horder JP, chairman. The paediatrics training required in the general practitioner. $\mathcal{f} R$ Coll Gen Pract 1976;26: the gen

6 Burke P, Bain J. Paediatric developmental screening: a survey of general practitioners. $\mathcal{F} R$ Coll Gen Pract 1986; 36:302-6.

\title{
Haem arginate in acute hereditary coproporphyria
}

\author{
D J Manning, T A Gray
}

\begin{abstract}
An 11 year old boy presented with severe acute hereditary coproporphyria. Despite supportive measures his condition deteriorated after admission. Haem arginate, started two days after presentation, produced appreciable inhibition of porphyrin precursor overproduction and clinical improvement.
\end{abstract}

Hereditary coproporphyria is the least common of the hepatic porphyrias. About $35 \%$ of cases present acutely. ' Recently haem arginate, a stable haem compound, has been shown to reduce porphyrin precursor overproduction during acute attacks. ${ }^{2}$ We report its use during severe acute hereditary coproporphyria.

\section{Case report}

An 11 year old boy was admitted after a generalised seizure. He was vomiting for nine days despite prochlorperazine and metoclopramide, and had lethargy, abdominal pain, and constipation for four days. He had eaten little in the week before admission. Apart from constipation he was previously well. His father, aged
44, had mild hypertension. Otherwise there was no significant family history.

On examination he was agitated and confused, but localising pain appropriately. Axillary temperature was $36.5^{\circ} \mathrm{C}$. The pupils were dilated but reactive, and there was no papilloedema. The ankle jerks were brisk, with clonus, and the plantar responses were equivocal. The pulse rate was $160 /$ minute and blood pressure $150 / 110 \mathrm{~mm} \mathrm{Hg}$. The precordial impulse was hyperdynamic. The respiratory rate was $16 /$ minute with shallow breaths. Abdominal examination was normal.

Investigations showed a normal peripheral white cell count and differential. Plasma urea concentration was $10 \mathrm{mmol} / 1$, glucose $9 \cdot 7 \mathrm{mmol}$ 1 , and electrolytes were normal. There was mixed respiratory and metabolic acidosis with arterial $\mathrm{pH} 7 \cdot 083$, carbon dioxide tension $8 \cdot 27$ $\mathrm{kPa}$, oxygen tension $14.4 \mathrm{kPa}$, and base excess $-12 \cdot 9$. Computed tomography of the brain was normal, and lumbar puncture showed normal cerebrospinal fluid.

Seizures persisted despite intravenous diazepam and he was given a single loading dose of intravenous phenytoin followed by a clonazepam infusion. Hypertension and tachycardia 